\title{
The Resistance Comparison Method Using Integral Controller for Photovoltaic Emulator
}

\author{
Razman Ayop", Chee Wei Tan², Cheng Siong Lim $^{3}$ \\ ${ }^{1,2}$ Departement of Electrical Power Engineering, Universiti Teknologi Malaysia \\ ${ }^{3}$ Department of Control and Mechatronic Engineering, Universiti Teknologi Malaysia
}

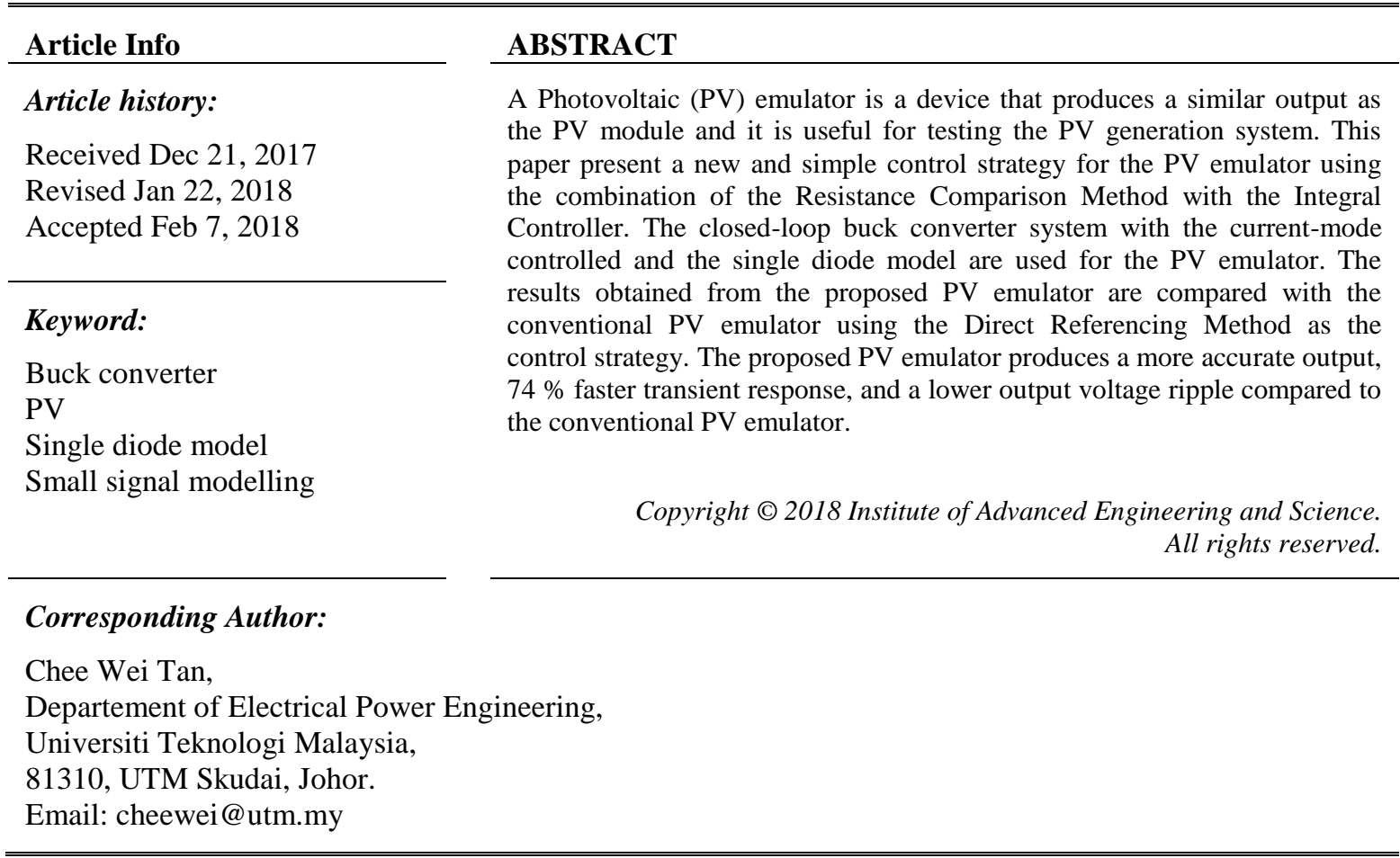

\section{INTRODUCTION}

The photovoltaic (PV) generation system has gain popularity in the energy sector. The world has gained interest in this system due to the government policies on the renewable energy, as well as the increases in the efficiency and the cost reduction of the PV panel. However, the energy produced by PV generation system is highly dependable on the ambient condition such as the irradiance and the temperature. While the output of the PV module is nonlinear, which further complicate the energy generation process. To ensure the maximum power is generated from the PV module, the Maximum Power Point Tracking (MPPT) is added into the PV generation system. In the MPPT research, the irradiance manipulation is essential to test the capability of the MPPT method. This leads to the used of controllable halogen lamp to control the irradiance for the PV panel. Nevertheless, this method is inefficient and requires a large area. Another way to test the MPPT is by using the PV emulator.

The PV emulator is a nonlinear Direct Current (DC) power supply that produces similar output as the PV module. The irradiance and the temperature are easier to control, is highly efficient, able to produce multiple different PV module characteristics, and requires a small testing area. There are three components in the PV emulator, which are the PV mathematical model, the power converter, and the control strategy [1]. The function of the PV mathematical model is to produce the Current-Voltage (I-V) characteristics curve of the PV module. The single diode model is commonly used in the PV emulator application as the PV mathematical model since this model is accurate and simple [2], [3]. The power converter emulates the I-V characteristics produced by the PV mathematical model. There are various topologies used in the PV emulator depending on the requirements of the system. However, the buck converter are widely used in the PV emulator application due to the simplicity, a low number of components, and easy to control [4], [5]. 
While the control strategy is the method used to integrate the PV mathematical model and the power converter into a PV emulator. The main function is to determine the operating point of the PV emulator. This means that the control strategy finds the voltage and the current on the I-V characteristics curve based on the load connected to the PV emulator.

The control strategy affects the steady state stability, the transient response, and the accuracy of the output for the PV emulator. The hardware platform used for the PV emulator is also affected by the control strategy. This is because different control strategies require different processing power and memory storage from the hardware platform. The Direct Referencing Method is commonly used control strategy for the PV emulator since it is simple to implement [6]-[8]. The operating point of the PV emulator is obtained from the external factors, which are the dynamic characteristic of the power converter and the PI controller. Due to the dependency of the control strategy on the external factors, the output of the PV emulator becomes oscillate at a certain load condition. The oscillating problem is overcome by using different control strategy such as the Hybrid-Mode Control Method [9] and the Resistance Comparison Method [10], [11]. The Hybrid-Mode Controlled Method combines two different Direct Referencing Methods (the current control and the voltage control) to prevent the oscillation problem. Nevertheless, the control is complex since there are two independent controllers are used to determine the one operating point for the PV emulator. The Resistance Comparison Method is simpler compared to the Hybrid-Mode Controlled Method. This control strategy tested multiple points on the I-V characteristics curve to determine the operating point. However, the tests are conducted at a fixed step size, which results in a slow computation of the operating point and a poor dynamic performance. There has been an improvement to solve the operating point for the Resistance Comparison Method by using the variable step sizes instead of a fixed step size. The Binary Search Method is implemented into the Resistance Comparison Method resulting a significantly faster computation of the operating point and produces a highly accurate output [12]. However, the Binary Search Method is complicated to implement.

A good control strategy needs to be simple likes the Direct Referencing Method while producing a non-oscillating and accurate operating point likes the Resistance Comparison Method with the variable step sizes. Nevertheless, the Direct Referencing Method produces oscilating operating points and the current Resistance Comparison Method with the variable step sizes is complex because of the Binary Search Method [12]. This shows the need for a simple and non-oscillating control strategy for the PV emulator. The Resistance Comparison Method with variable step sizes has a good potential as the control strategy for the $\mathrm{PV}$ emulator if this method is easy to implement. The function of the Binary Search Method in the Resistance Comparison Method with the variable step is to produe the output depending on the input error. This function is also similar to the easily implemented integral controller. Therefore, it is possible to simplify the design of the current Resistance Comparison Method with the variable step by replacing the Binary Search Method with the integral controller.

This paper discusses a new simple control strategy for the PV emulator using the Resistance Comparison Method. The operating point produced by the Resistance Comparison Method is computed using the integral controller, which produce variable step sizes. The buck converter is used for the PV emulator and it operates in the continuous current mode with the at most $1 \%$ output voltage ripple factor. The closed-loop power converter system is controlled using the PI controller and it operates in the current-mode controlled. The PV mathematical model used for the PV emulator is the single diode model. The simulation is conducted using MATLAB/Simulink ${ }^{\circledR}$ simulation package.

\section{COMPONENTS OF PHOTOVOLTAIC EMULATOR}

\subsection{Photovoltaic Model}

The PV mathematical model is used to generate the I-V characteristic of the PV module. The single diode model is a common PV mathematical model in the PV emulator application. The photovoltaic module current, $I_{\mathrm{pv}}$, is calculated using (1) [13]:

$$
I_{p v}=I_{p h}-I_{s}\left[\exp \left(\frac{V_{p v}+I_{p v} R_{s}}{V_{t} A}\right)-1\right]-\frac{V_{p v}+I_{p v} R_{s}}{R_{p}}
$$

where $I_{p h}$ is the photo-generated current (A), $I_{s}$ is the diode saturated current $(A), V_{p v}$ is the photovoltaic module voltage $(\mathrm{V}), \mathrm{R}_{\mathrm{s}}$ is the series resistance $(\Omega), \mathrm{V}_{\mathrm{t}}$ is the junction thermal voltage, where $V_{t}=k T / q, \mathrm{k}$ is the Boltzmann constant $\left(1.38 \times 10^{-23} \mathrm{~J} / \mathrm{K}\right), \mathrm{T}$ is the module temperature $(\mathrm{K}), \mathrm{q}$ is the electron charge $\left(1.602 \times 10^{-}\right.$ ${ }^{19} \mathrm{C}$ ), A is the ideality factor, and $\mathrm{R}_{\mathrm{p}}$ is the parallel resistance $(\Omega)$.

The Newton-Raphson Method is used to solve (1) since it is an implicit equation. The irradiance and temperature affect $I_{p h}$, which is calculated using (2) [1]. $I_{s}$ only depends on the temperature which is 
calculated using (3) [14]. The characteristic of the PV module is listed in Table $1 . \mathrm{R}_{\mathrm{s}}$ and $\mathrm{R}_{\mathrm{p}}$ is determine using the parameter extraction process [15].

$$
\begin{aligned}
& I_{p h}=\frac{G}{1000}\left[I_{s c}+\alpha(T-25)\right] \\
& I_{S}=\frac{I_{s c}}{\exp \left(V_{o c} / \mathrm{V}_{\mathrm{t}} A\right)-1}
\end{aligned}
$$

where $\mathrm{G}$ is the irradiance $\left(\mathrm{W} / \mathrm{m}^{2}\right), \mathrm{STC}$ is the Standard Test Condition $\left(1000 \mathrm{~W} / \mathrm{m}^{2}, 25{ }^{\circ} \mathrm{C}\right), \mathrm{I}_{\mathrm{sc}}$ is the short circuit current during STC (A), $\alpha$ is the temperature coefficient of $\mathrm{I}_{\mathrm{sc}}, \mathrm{T}$ is the temperature $\left({ }^{\circ} \mathrm{C}\right), \mathrm{V}_{\mathrm{oc}}$ is the open circuit voltage during STC (V).

Table 1. Photovoltaic module characteristic of the SPM050-M PV panel [16]

\begin{tabular}{ll}
\hline \multicolumn{1}{c}{ Parameter } & \multicolumn{1}{c}{ Value } \\
\hline Open Circuit Voltage, $\mathrm{V}_{\mathrm{oc}}$ & $22.53 \mathrm{~V}$ \\
Short Circuit Current, $\mathrm{I}_{\mathrm{sc}}$ & $2.97 \mathrm{~A}$ \\
Maximum Power Point Voltage, $\mathrm{V}_{\mathrm{mp}}$ & $18.68 \mathrm{~V}$ \\
Maximum Power Point Current, $\mathrm{I}_{\mathrm{mp}}$ & $2.77 \mathrm{~A}$ \\
Temperature Coefficient of $\mathrm{V}_{\mathrm{oc}}, \beta$ & $-0.35 \% /{ }^{\circ} \mathrm{C}$ \\
Temperature Coefficient of $\mathrm{I}_{\mathrm{sc}}, \alpha$ & $0.05 \% /{ }^{\circ} \mathrm{C}$ \\
\hline
\end{tabular}

\subsection{Buck Converter}

The buck converter, shown in

Figure 1(a), is commonly used in the PV emulator application due to the simplicity, a low number of components, and have a high efficiency. There are two considerations in designing the buck converter, which is the continuous current mode and the output voltage ripple factor. The continuous current mode operation is chosen since the design is simpler and the operation is more stable compared to the discontinuous current mode. The continuous current mode depends on the buck converter inductance, L, which is calculated using (4) [17]. The output voltage ripple factor, $\gamma_{V_{0}}$, needs to be lower than $1 \%$ to ensure accurate emulation of the PV module. This is because the PV module does not contain output ripple and it is essential to keep the output voltage ripple of the PV emulator as low as possible. The output voltage ripple factor depends on the capacitance of the buck converter, C, which is calculated using (5) [17].

$$
\begin{aligned}
& L=\frac{(1-D) R_{O}}{2 f} \\
& C=\frac{1-D}{8 L \gamma_{V o} f^{2}}
\end{aligned}
$$

where $\mathrm{D}$ is the duty cycle, $\mathrm{R}_{\mathrm{o}}$ is the output resistance, and $\mathrm{f}$ is the switching frequency.

The PI controller is important to obtain a good transient response and zero steady state error. The tuning of the PI controller requires the transfer function of the buck converter, $G_{b}$, as shown in (6) [10]. While the transfer function of the PI controller, $G_{c}$, is shown in (7) [10].

$$
\begin{aligned}
& G_{b}(s)=\frac{\hat{\imath}_{o}}{\hat{d}}=\frac{V_{i}}{R_{o}} \frac{1 / L C}{s^{2}+1 / R_{o} C^{S+1 / L C}} \\
& G_{C}(s)=K_{p}+\frac{K_{i}}{s}
\end{aligned}
$$

where $\mathrm{K}_{\mathrm{p}}$ is the proportional gain and $\mathrm{K}_{\mathrm{i}}$ is the integral gain.

The arrangement of the closed-loop buck converter system is shown in

Figure $1(\mathrm{~b})$. The tuning of the PI controller is focused on the lower limit of $\mathrm{R}_{\mathrm{o}}$ since the transient response for the buck converter is the fastest during this load condition. The parameter for the buck converter and the PI controller is shown in

Table 2.

Int J Pow Elec \& Dri Syst, Vol. 9, No. 2, June 2018 : 820-828 


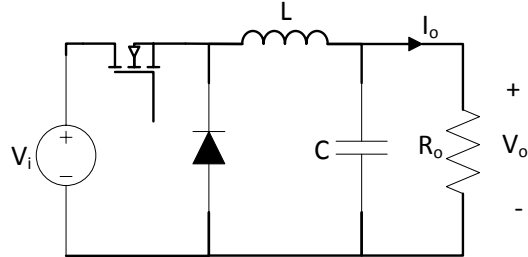

(a)

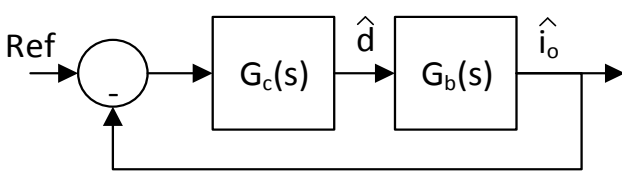

(b)

Figure 1. (a) The buck converter and (b) the closed-loop buck converter system.

Table 2. The parameter of the closed-loop buck converter system.

\begin{tabular}{lr}
\hline \multicolumn{1}{c}{ Parameter } & \multicolumn{1}{c}{ Value } \\
\hline Input Voltage, $\mathrm{V}_{\mathrm{i}}$ & $30 \mathrm{~V}$ \\
Switching Frequency, $\mathrm{f}$ & $20 \mathrm{kHz}$ \\
Output Resistance, $\mathrm{R}_{\mathrm{o}}$ & $3 \mathrm{to} 50 \Omega$ \\
Inductance, $\mathrm{L}$ & $1.8 \mathrm{mH}$ \\
Inductor Internal Resistance, $\mathrm{r}_{\mathrm{L}}$ & $0.36 \Omega$ \\
Capacitance, C & $39 \mu \mathrm{F}$ \\
Capacitor Internal Resistance, $\mathrm{r}_{\mathrm{C}}$ & $0.025 \Omega$ \\
MOSFET Drain-Source Resistor, $\mathrm{R}_{\mathrm{ds}(\mathrm{on})}$ & $0.0106 \Omega$ \\
Diode Forward Voltage, $\mathrm{V}_{\mathrm{f}}$ & $0.44 \mathrm{~V}$ \\
Proportional Gain, $\mathrm{K}_{\mathrm{p}}$ & 0.12392 \\
Integral Gain, $\mathrm{K}_{\mathrm{i}}$ & 234.33644 \\
\end{tabular}

\section{PROPOSED CONTROL STRATEGY}

The proposed PV emulator is shown in

Figure 2. It is a closed-loop buck converter system using current-mode controlled. The reference input of the closed-loop buck converter system is connected with the proposed Resistance Comparison Method using the integral controller. By referring to

Figure 2, the output voltage, $V_{0}$, and the output current, $I_{0}$, of the PV emulator is measured. Vo is then divided with Io to digitally obtain $R_{o}$. $R_{o}$ is compared with the $R_{p v}$, which is obtained by dividing $V_{p v}$ over $I_{p v}$. The Resistance Comparison error, $E_{r}$, becomes the input of the integral controller, $G_{i}$. $G_{i}$ is calculated using (8):

$$
G_{i}(s)=\frac{\gamma_{K i} K_{i}}{s}
$$

where $\gamma_{\mathrm{Ki}}$ the integral gain amplification factor. 

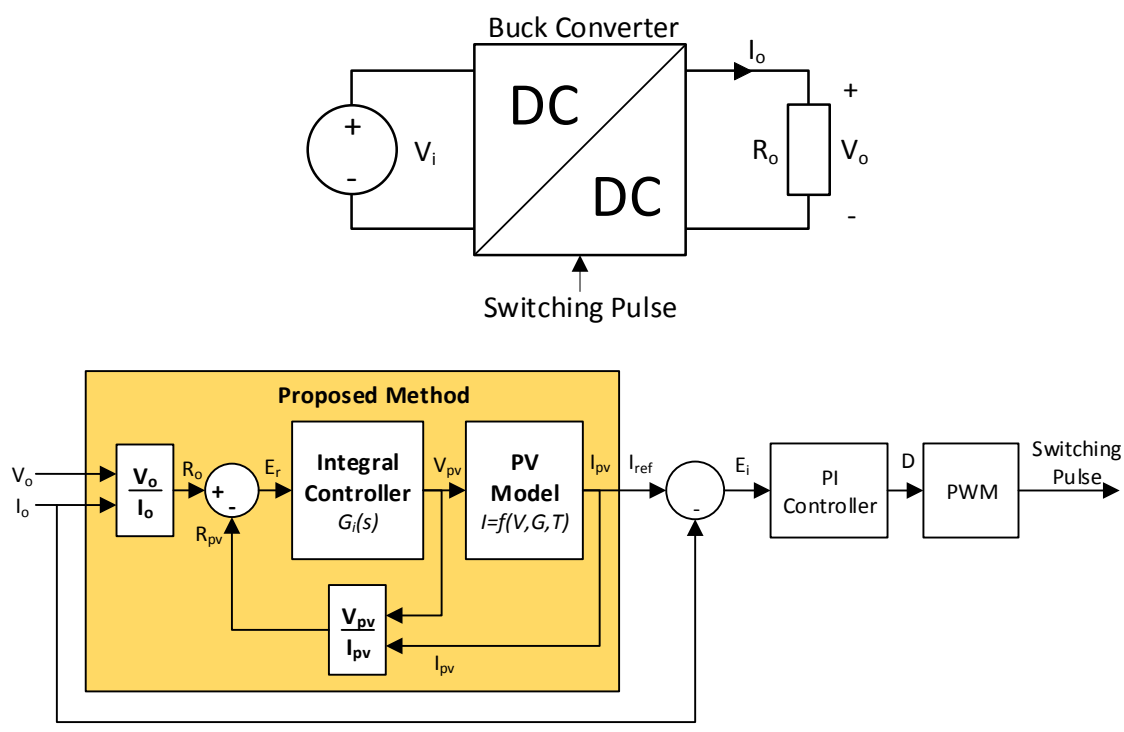

Figure 2. The block diagram of the proposed Resistance Comparison Method using the integral controller.

In an ideal condition, $\gamma_{\mathrm{Ki}}$ is set to infinity for an instantaneous operating point computation. However, the discrete characteristic of the digital controller prevents $\gamma_{\mathrm{Ki}}$ to be set to infinity. $\gamma_{\mathrm{Ki}}$ is carefully selected to allow the hardware platform to cope with the processing burden. In this simulation, the sample time for the controller is set to $20 \mu \mathrm{s}$. This is done by using the discrete PI controller block and zero-order hold block in the MATLAB/Simulink ${ }^{\circledR}$ 's library. Using Try and Error Method, $\gamma_{\mathrm{Ki}}$ is increased from 1 and stop when the reference input becomes oscillates. From the tuning process, the optimum $\gamma_{\mathrm{Ki}}$ is 2.5. Besides $\gamma_{\mathrm{Ki}}$, the initial output of the integral controller is increased. This is done to prevent spike during the start-up process of the PV emulator. The recommended initial output for the integral controller is the open circuit voltage during the lowest irradiance. For this simulation, the initial output of the integral controller is $15 \mathrm{~V}$. The output of the integral controller is $\mathrm{V}_{\mathrm{pv}}$ for the PV mathematical model. The PV mathematical model produces $I_{p v}$ corresponding to the $V_{p v}$. $R_{p v}$ is calculated again with $R_{o}$. This process is repeated until $E_{r}$ is very small.

\section{RESULTS AND DISCUSSIONS}

The results from the proposed PV emulator is compared with the conventional PV emulator using the Direct Referencing Method [6-8]. The optimum PI controller shown in

Table 2 could not be used for the Direct Referencing Method due to the oscillation problem at a certain load condition [1]. To overcome this problem, the $\mathrm{K}_{\mathrm{p}}$ and $\mathrm{K}_{\mathrm{i}}$ is reduced to $80 \%$ to become 0.0248 and 46.8673 respectively. The results obtained from the PV emulators are based on the temperature of $25^{\circ} \mathrm{C}$.

\subsection{Accuracy}

The accuracy of the PV emulator depends on the PV mathematical model and the control strategy. To test the accuracy of the PV mathematical model, the I-V characteristic produced by this model is compared with the $I-V$ characteristic obtained from the PV panel. However, to test the accuracy of the control strategy, the I-V characteristic curve obtained from the output of the PV emulator is compared with the PV mathematical model. This step is taken to ensure that the error produced by the PV mathematical model is not taken into the results and only error produced by the control strategy is considered. Therefore, $V_{o}$ and $I_{o}$ obtained from the PV emulator are compared with the I-V characteristic curve produced by the PV mathematical model, as

Figure 3(a). shown in

An accurate control strategy able to produce the output of the PV emulator similar to the I-V characteristic curve of the PV mathematical model. If the current-mode controlled is used for the closed-loop power converter system, the output of the PV emulator becomes oscillate in the constant voltage region. This is because a small change in Vpv produces a large change $I_{p v}$ for the PV mathematical model. Therefore, analysis of the accuracy is focused in the constant voltage region, as shown in 
Figure $3(b)$. The simulations are conducted with nine different $R_{o}$ ranging from $3 \Omega$ to $50 \Omega$. The irradiance is set at $200 \mathrm{~W} / \mathrm{m}^{2}$ and $1000 \mathrm{~W} / \mathrm{m}^{2}$. Each simulation is conducted for $0.3 \mathrm{~s}$ to ensure the PV emulator reaches the steady state condition. $V_{o}$ and $I_{o}$ obtained from the conventional PV emulator using the Direct

Figure 3(a).

The $V_{o}$ and $I_{o}$ produced by the conventional and proposed $P V$ emulator is accurate in the constant current region, as shown in

Figure 3(a). The accurate results are observed when the output of the PV emulator is on the I-V characteristics curve produced by the PV mathematical model. Nevertheless, the output of the PV emulator becomes inaccurate when operates in the constant voltage region, as shown in

Figure $3(\mathrm{~b})$. During this condition, $\mathrm{R}_{\mathrm{o}}$ connected to the conventional PV emulator is $31 \Omega$ and $50 \Omega$. The inaccurate output produced by the conventional PV emulator is caused by the unstable reference input and oscillation of $V_{o}$ and $I_{0}$. While $50 \Omega$ of $R_{o}$ is connected to the proposed PV emulator when the inaccurate output is produced. The inaccurate output produced by the proposed PV emulator is caused by the limitation of the digital controller. This can be solved with a lower sampling time of the digital controller. To reduce the sampling time, a hardware platform with a higher processing power is needed.

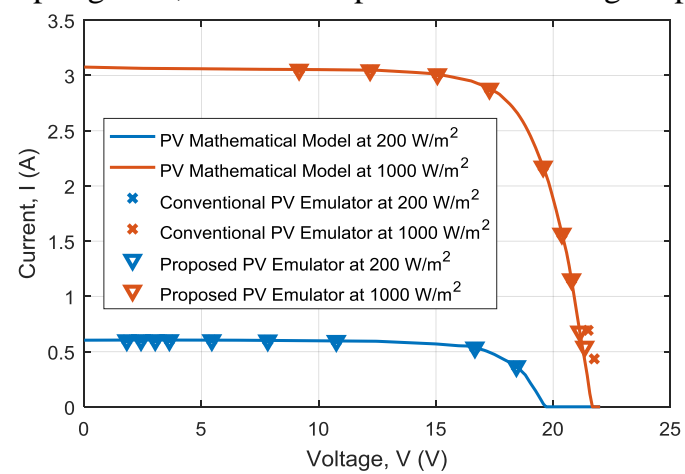

(a)

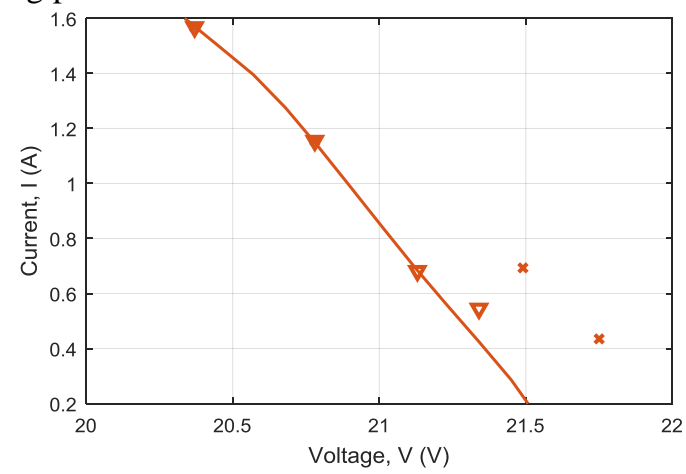

(b)

Figure 3. a) The I-V characteristics curve of the PV mathematical model, conventional PV emulator, and the proposed PV emulator during $200 \mathrm{~W} / \mathrm{m}^{2}$ and $1000 \mathrm{~W} / \mathrm{m}^{2}$. b) The zoom-in view of

Figure 3

\subsection{Transient Response}

The transient response of the PV emulator is also an important factor that needs to be considered in the design. The slow transient response of the PV emulator can cause the MPPT converter connected to the PV emulator operates inaccurately. To prevent this, the PV emulator is designed to operate with a fast transient response.

There are two components that affect the transient response of the PV emulator, which are the power converter and the control strategy. Choosing a higher switching frequency can result in a faster transient response since the inductance and the capacitance used in the power converter becomes smaller. The different topologies of the power converter also affect the transient response of the PV emulator. Besides power converter, control strategy also affects the transient response of the PV emulator. Therefore, the analysis is conducted on the proposed control strategy to compare the transient response improvement against the conventional PV emulator.

In the simulations, two different $R_{o}$ is tested on the conventional and proposed PV emulator, as shown in Figure 4(a) and

Figure $4(b)$. The $R_{o}$ chosen is the minimum and maximum $R_{o}$ limits, which are $3 \Omega$ and $50 \Omega$ respectively. When $3 \Omega$ is connected to the PV emulator, the system operates in the constant current region. The settling time for the conventional and proposed $P V$ emulator is $9.4 \mathrm{~ms}$ and $2.4 \mathrm{~ms}$ respectively. The proposed PV emulator is $74 \%$ faster compared to the conventional PV emulator. This slow response of the conventional PV emulator is due to the $80 \%$ gains reduction in the PI controller to compensate the oscillation problem. Even though the gains are reduced up to $80 \%$, there is still an output current oscillation occur, as shown in

Figure 4(b). The proposed PV emulator is not affected by the PI controller and the buck converter parameters. As a result, there no gains reduction needed on the PI controller and the optimum PI controller design can be used. This results in a fast transient response for the proposed PV emulator.

When $50 \Omega$ is connected to the PV emulator, the system operates in constant voltage region. The settling time for the conventional and proposed PV emulator is $5.4 \mathrm{~ms}$ and $28.2 \mathrm{~ms}$ respectively. The

The Resistance Comparison Method using Integral Controller for Photovoltaic Emulator (R. Ayop) 
proposed PV emulator is 5.2 times slower than the conventional PV emulator. The proposed PV emulator with $50 \Omega \mathrm{R}_{\mathrm{o}}$ is 11.8 times lower than the proposed PV emulator with $3 \Omega \mathrm{R}_{\mathrm{o}}$. The transient response of the proposed PV emulator becomes slower as $\mathrm{R}_{\mathrm{o}}$ increases. This is due to the design of the PI controller. The PI controller is designed for the range of $R_{o}$, which is $3 \Omega$ to $50 \Omega$. The transient response of the closed-loop buck converter system becomes more aggressive as $R_{0}$ decreases. Therefore, the tuning of the PI controller is conducted at the lower limit of $R_{0}$, which is $3 \Omega$. This results in a slower transient response as $R_{o}$ increases. The transient response of the conventional PV emulator also becomes slower as $R_{o}$ increases in the constant current region. However, the response becomes faster as $R_{0}$ increases in the constant voltage region. This is because the $\mathrm{I}_{\text {ref }}$ produces by the Direct Referencing Signal is very high during the start-up of the PV emulator.
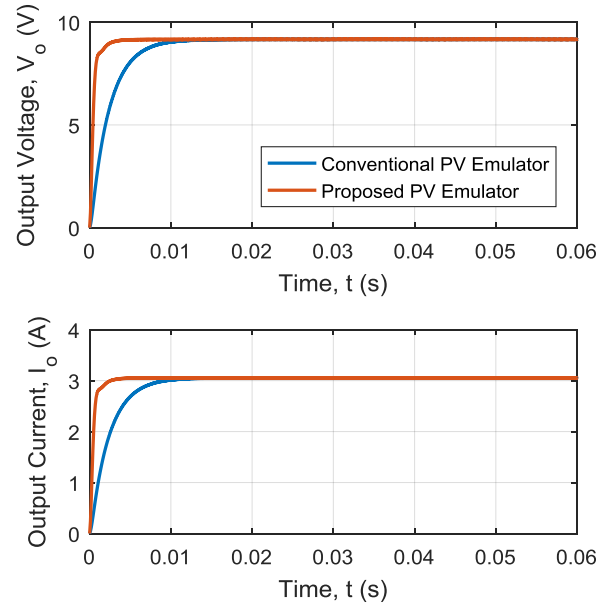

(a)
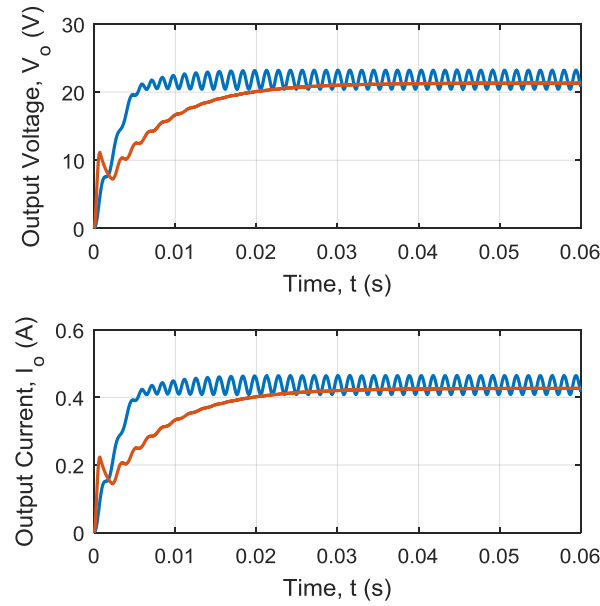

(b)

Figure 4. The output voltage and output current of the conventional and proposed PV emulator during $1000 \mathrm{~W} / \mathrm{m}^{2}$ with different output resistance. a) The minimum output resistance $(3 \Omega)$. b) The maximum output resistance $(50 \Omega)$.

\subsection{Output Voltage Ripple}

The buck converter is one of the Switched-Mode Power Supply (SMPS). The advantage of the buck converter is it has a higher efficiency compared to the linear voltage regulator [17]. Nevertheless, the output voltage produced by the buck converter contain ripple. The output voltage ripple is manipulated by calculating $\mathrm{C}$ using (5). In the PV emulator application, the output voltage ripple is not only affected by the buck converter design but also the control strategy [1]. This is because the control strategy such as the Direct Referencing Method produced unwanted oscillation that results in a higher output voltage ripple factor, $\gamma_{\mathrm{Vo}}$. As Ro increases, $V_{o}$ increases. The increases in $V_{o}$ is caused by the increases in D. By referring to (5), if $L$ and $C$ are kept fixed, the increases in D results in a lower $\gamma_{V o}$. However, the conventional PV emulator does not follow this characteristic, as shown in

Figure 5. The $\gamma_{v_{0}}$ decreases as $R_{o}$ increased up to $29 \Omega$. When $R_{o}$ is $30 \Omega, \gamma_{v_{0}}$ increases up to 44.6 times. The sudden increase in $\gamma_{V_{0}}$ is caused by the weakness of the Direct referencing Method. This unwanted oscillation is reduced by decreasing the gains of the PI controller. Since the gains in the PI controller is already reduced to $80 \%$, further decreases the gains results in a slower transient response.

The proposed $P V$ emulator eliminates the unwanted oscillation, as shown in

Figure 5. The $\gamma_{V_{0}}$ decreases as $R_{o}$ decreases, which follow (5). This shows that the proposed PV emulator is a robust control strategy since it is not affected by the external factors such as PI controller and the parameters of the buck converters. 


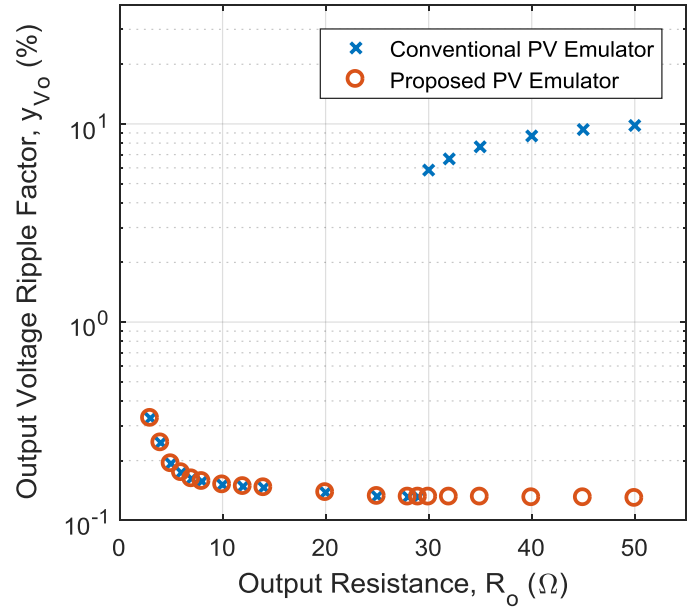

Figure 5. The output voltage ripple factor for the conventional and proposed PV emulator during $1000 \mathrm{~W} / \mathrm{m}^{2}$. 5. CONCLUSION

A new control strategy for the PV emulator has been designed using the Resistance Comparison Method with variable step sizes. The variable step sizes are computed using a simple integral controller. The proposed PV emulator shows higher output accuracy compared to the conventional PV emulator. The accuracy of proposed method depends on the sampling time of the digital hardware platform. As a result, the integral controller requires tuning based on the sampling time. The transient response of the proposed PV emulator is improved significantly in the constant current region. However, the transient response becomes slower as the output resistance increases. This is due to the weakness the PI controller. It is recommended to use a more robust controller as the replacement for the PI controller to overcome slow transient response. The proposed PV emulator is also more robust compared to the conventional PV emulator. This is because the control strategy used in the proposed PV emulator is not affected by the external factor such as the PI controller and the parameters of the buck converter. It is hoped that the simple adjustment made to the conventional PV emulator is easily implemented and allows significant improvement on the performance of the PV emulator.

\section{ACKNOWLEDGEMENTS}

The authors would like to pay gratitude to Universiti Teknologi Malaysia (UTM) for supporting with lab and library facilities. In addition, the authors would like to express their appreciation to the Ministry of Higher Education, Malaysia (MOHE). They also acknowledge funding provided by fundamental research grant scheme (FRGS) under vote 4F596, Universiti Teknologi Malaysia (UTM). Razman Ayop acknowledges the financial support from the Ministry of Higher Education Malaysia (MOHE) under MyBrain15 scheme. Lastly thanks to those colleagues who have either directly or indirectly contributed to the completion of this work.

\section{REFERENCES}

[1] R. Ayop and C. W. Tan, "A comprehensive review on photovoltaic emulator," Renewable and Sustainable Energy Reviews, vol. 80, pp. 430-452, 12// 2017.

[2] Z. Weichao and J. W. Kimball, "DC-DC converter based photovoltaic simulator with a double current mode controller," in 2016 IEEE Power and Energy Conference at Illinois (PECI), 2016, pp. 1-6.

[3] M. Balato, L. Costanzo, D. Gallo, C. Landi, M. Luiso, and M. Vitelli, "Design and implementation of a dynamic FPAA based photovoltaic emulator," Solar Energy, vol. 123, pp. 102-115, 1// 2016.

[4] M. T. Iqbal and M. Tariq, "Modeling, Analysis and Control of Different DC-DC Converter Topologies for Photo Voltaic Emulator," International Journal of Applied Power Engineering (IJAPE), vol. 6, pp. 46-55, 2017.

[5] F. Yusivar, M. Farabi, R. Suryadiningrat, W. Ananduta, and Y. Syaifudin, "Buck-converter photovoltaic simulator," International Journal of Power Electronics and Drive Systems, vol. 1, p. 156, 2011.

[6] A. Koran, T. LaBella, and J. S. Lai, "High Efficiency Photovoltaic Source Simulator with Fast Response Time for Solar Power Conditioning Systems Evaluation," IEEE Transactions on Power Electronics, vol. 29, pp. 1285-1297, 2014.

[7] J. Zhang, S. Wang, Z. Wang, and L. Tian, "Design and realization of a digital PV simulator with a push-pull forward circuit," Journal of Power Electronics, vol. 14, pp. 444-457, 2014.

[8] F. J. Viglus and M. M. Casaro, "Photovoltaic array emulation using a three-phase DC-DC converter with galvanic isolation," in 2016 12th IEEE International Conference on Industry Applications (INDUSCON), 2016, pp. 1-8.

The Resistance Comparison Method using Integral Controller for Photovoltaic Emulator (R. Ayop) 
[9] Y. Kim, W. Lee, M. Pedram, and N. Chang, "Dual-mode power regulator for photovoltaic module emulation," Applied energy, vol. 101, pp. 730-739, 2013.

[10] C. H. Balakishan and N. Sandeep, "Development of a Microcontroller Based PV Emulator with Current Controlled DC-DC Buck Converter "International Journal of Renewable Energy Research, vol. 4, p. 1, 22/11/14 2014.

[11] A. V. Rana and H. H. Patel, "Current controlled buck converter based photovoltaic emulator," Journal of Industrial and Intelligent Information, vol. 1, 2013.

[12] R. Ayop and C. W. Tan, "Improved control strategy for photovoltaic emulator using resistance comparison method and binary search method," Solar Energy, vol. 153, pp. 83-95, 9/1/ 2017.

[13] R. Ayop and C. W. Tan, "An Adaptive Controller for Photovoltaic Emulator using Artificial Neural Network," Indonesian Journal of Electrical Engineering and Computer Science, vol. 5, pp. 556-563, 2017.

[14] D. Ickilli, H. Can, and K. S. Parlak, "Development of a FPGA-based photovoltaic panel emulator based on a DC/DC converter," in Photovoltaic Specialists Conference (PVSC), 2012 38th IEEE, 2012, pp. 001417-001421.

[15] V. J. Chin, Z. Salam, and K. Ishaque, "Cell modelling and model parameters estimation techniques for photovoltaic simulator application: A review," Applied Energy, vol. 154, pp. 500-519, 2015/09/15/ 2015.

[16] "Mono-Crystalline 50Wp Solar Module SPM050-M," S. P. Mart, Ed., ed.

[17] D. W. Hart, Power Electronics. Valparaiso University, Indiana: Tata McGraw-Hill Education, 2011.

\section{BIOGRAPHIES OF AUTHORS}

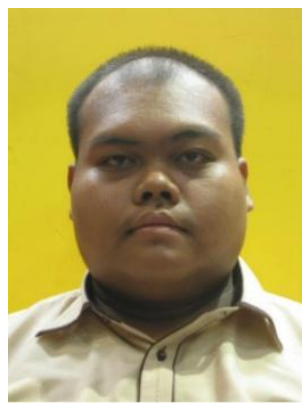

Razman Ayop received his bachelor and master degree in Electrical Engineering from the Universiti Teknologi Malaysia, Johor, Malaysia in 2013 and 2015 respectively. He is currently working toward the Ph.D. degree in Electrical Engineering at Universiti Teknologi Malaysia, Johor, Malaysia. His research interests include the renewable energy, the power electronic, the photovoltaic emulator, and the maximum power point tracking converter.

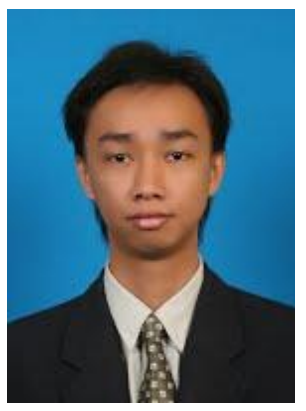

Chee Wei, Tan received his B.Eng. degree in electrical engineering (first class honors) from Universiti Teknologi Malaysia (UTM), in 2003 and the Ph.D. degree in electrical engineering from Imperial College London, London, U.K., in 2008. He is a senior lecturer with Universiti Teknologi Malaysia and a member of the Department of Electrical Power, Faculty of Electrical Engineering. His research interests include the application of power electronics in renewable/alternative energy systems and control of power electronics.

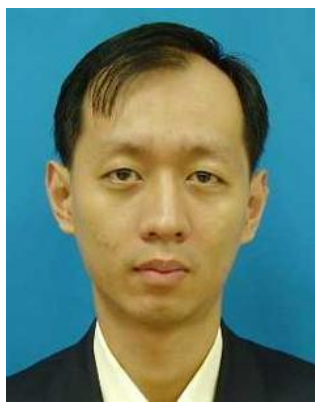

Cheng Siong, Lim received his B. Eng. degree in Electrical Engineering (first class honors), M. Eng degree (Electrical), and Ph.D. degree from Universiti Teknologi Malaysia (UTM), in 1999, 2004, and 2011, respectively. He is a senior lecturer at UTM, a faculty member of the Department of Control and Mechatronic Engineering, Faculty of Electrical Engineering. His research interests are in embedded system, emergency medical services, telerobotics and multiagent system. 